\title{
Assinatura geofísica e modelos prospectivos 'knowledge-driven' de mineralizações de Au no lineamento Congonhas, sul do Cráton São Francisco, $\mathrm{MG}$
}

\author{
Carolina Miethke ${ }^{1}$, Carlos Roberto de Souza Filho ${ }^{2}$ \& Adalene Moreira Silva ${ }^{3}$
}

\begin{abstract}
Resumo Este trabalho aborda a caracterização da assinatura geofísica de ocorrências auríferas associadas ao Lineamento Congonhas - uma zona de cisalhamento de escala regional, localizada na região sul do Quadrilátero Ferrífero (MG) - visando a geração de modelos prospectivos para mineralizações de ouro do tipo lode através da fusão e análise espacial de dados digitais. Para este estudo, dados aerogeofísicos, multiespectrais (orbitais), mapas geológicos e de ocorrências minerais foram investigados individualmente e de forma integrada. O processamento digital de dados conduzido incluiu realce por técnicas convencionais (composições coloridas, classificação não-supervisionada e análise por principais componentes), análises espaciais guiadas pelo conhecimento (knowledge-driven - lógicas booleana e fuzzy), bem como aplicação de técnicas originalmente desenvolvidas para classificação de dados de sensoriamento remoto hiperespectral (Spectral Angle Mapper e Mixture Tuned Matched Filtering), aqui adaptadas para uso com dados aerogeofísicos. Os resultados derivados do processamento, integração e interpretação dos dados revelaram que os métodos de análise espacial e classificação utilizados foram efetivos na seleção de alvos potencialmente mineralizados em ouro - sítios com ocorrências conhecidas desse metal, associadas à presença de unidades litológicas afetadas pelo hidrotermalismo decorrente da instalação do Lineamento Congonhas, foram mapeados com sucesso, assim como outras áreas onde tais ocorrências ainda não foram verificadas.
\end{abstract}

Palavras-chave: sensoriamento remoto, aerogeofísica, mineralizações de ouro, Quadrilátero Ferrífero

\begin{abstract}
Geophysical signature and knowledge-driven prospective models for Au mineralizations in the Congonhas lineament, south São Francisco Craton, MG. This research focused on identifying and describing geologic-geophysical signatures of gold occurrences associated with a regional scale shear zone (Congonhas Shear Zone), south of the Iron Quadrangle in the State of Minas Gerais, Brazil. The work aimed at combining and analyzing digital spatial data and developing predictive models for lode-type gold mineralization. Aerogeophysical and multispectral orbital data, in addition to geological and gold occurrence maps, were employed both separately and in an integrated approach. The digital processing steps involved several enhancement techniques - conventional (pseudocolor compositions, unsupervised classification and principal component analysis), knowledge-driven (boolean and fuzzy logic), as well as techniques originally developed for the classification of hyperspectral remote sensing data (Spectral Angle Mapper and Mixture Tuned Matched Filtering), which were here adapted to aerogeophysical data processing. The results yielded by the processing, integration and interpretation steps proved the spatial analysis and classification methods to be effective in the selection of targets potentially mineralized in gold. Sites with known occurrences of this metal, associated to lithological units affected by hydrothermal alteration related to the Congonhas shear zone, were successfully mapped. Additionally, other key areas, where no gold occurrences are known, were also individualized and will require further field verification to be validated.
\end{abstract}

Keywords: remote sensing, airborne geophysics, gold mineralization, Quadrilatero Ferrifero

INTRODUÇ̃̃O A porção Sul do Cráton São Francisco (CSF), incluindo o Quadrilátero Ferrífero (QF), no Estado de Minas Gerais, é uma das maiores províncias metalíferas do Brasil, com destaque para bens minerais como minérios de ferro e ouro. Um tipo importante de mineralização aurífera - os depósitos do tipo lode - ocorre associado a zonas de cisalhamento de grande escala nesta região.

A maioria dos depósitos auríferos do segmen- to Sul do CSF foi descoberta utilizando-se métodos convencionais de prospecção. No entanto, somente a utilização de tais métodos limita a identificação de novos depósitos devido à carência de mapeamentos geológicos sistemáticos e de informações detalhadas sobre a metalogênese e o controle estrutural das mineralizações. O emprego de métodos indiretos de prospecção, baseados em aerogeofísica, sensoriamento remoto e modelagem de dados espaciais e sua interpretação de

1 - Schlumberger Servicos de Petroleo Ltda., Macaé, RJ, Brasil. E-mail: cmiethke@macae.oilfield.slb.com

2 - Instituto de Geociências, Universidade Estadual de Campinas, Campinas, SP, Brasil. E-mail: beto@ige.unicamp.br

3 - Instituto de Geociências, Universidade de Brasília, Brasília, DF, Brasil. E-mail: adalene@unb.br 
forma integrada, ainda foi pouco explorado na região.

Nesse sentido, esse trabalho objetiva avaliar a assinatura geológico-geofísica de ocorrências auríferas associadas a uma zona de cisalhamento de escala regional, denominada Lineamento Congonhas (Seixas 1988), situada a Sul do $\mathrm{QF}$, visando à geração de modelos prospectivos para mineralizações de ouro do tipo lode através da fusão e análise espacial de dados digitais. Para tal, dados de ocorrências auríferas são integrados a dados de levantamento aerogeofísico de alta resolução e densidade de amostragem, imagens multiespectrais de sensoriamento remoto e outros dados geológicos, e analisados segundo modelos de análise espacial guiados pelo conhecimento (knowledge-driven), bem como através de técnicas originalmente desenvolvidas para classificação de dados de sensoriamento remoto hiperespectral, as quais são aqui adaptadas para classificação orientada dos dados aerogeofísicos.

As minas e os garimpos presentes na área são utilizados como pontos de treinamento genuínos para a realização e verificação dos resultados derivados da modelagem dos dados e previsão de áreas com maior favorabilidade prospectiva para ouro.

A área de estudo abrange os municípios de Congonhas, Conselheiro Lafaiete, Itaverava e Catas Altas da Noruega, balizada pelas coordenadas UTM 618070 e 659400 E e 7734700 e 7704570 N, e compreende cerca de $120 \mathrm{~km}^{2}$ (Fig. 1).

GEOLOGIA LOCAL E ESTRUTURAL Em contraste com o acervo bibliográfico sobre a geologia do Quadrilátero errífero, no qual se encontra inserida, são escassas as publicações referentes à geologia da área de estudo (Fig. 2).

Merece destaque o trabalho de Seixas (1988), que individualizou as seguintes unidades litoestruturais: (I) ortognaisses Alto Maranhão, (II) rochas supracrustais, (III) uma zona de transição milonítica entre as duas anteriores e (IV) o granitóide Congonhas. Ocorrem, subordinadamente, rochas dos Grupos Itacolomi e Piracicaba (Supergrupo Minas).

Os litotipos da unidade ortognaisses Alto Maranhão estão associados aos complexos granitóide-gnáissicos que formam o embasamento da região. Correspondem a hornblenda-biotita-gnaisses de composição tonalítica a quartzo-diorítica. Localmente, observam-se estruturas decorrentes de cisalhamento, com a formação de milonitos e fraturas.

As rochas supracrustais podem ser diretamente correlacionadas ao Supergrupo Rio das Velhas, que

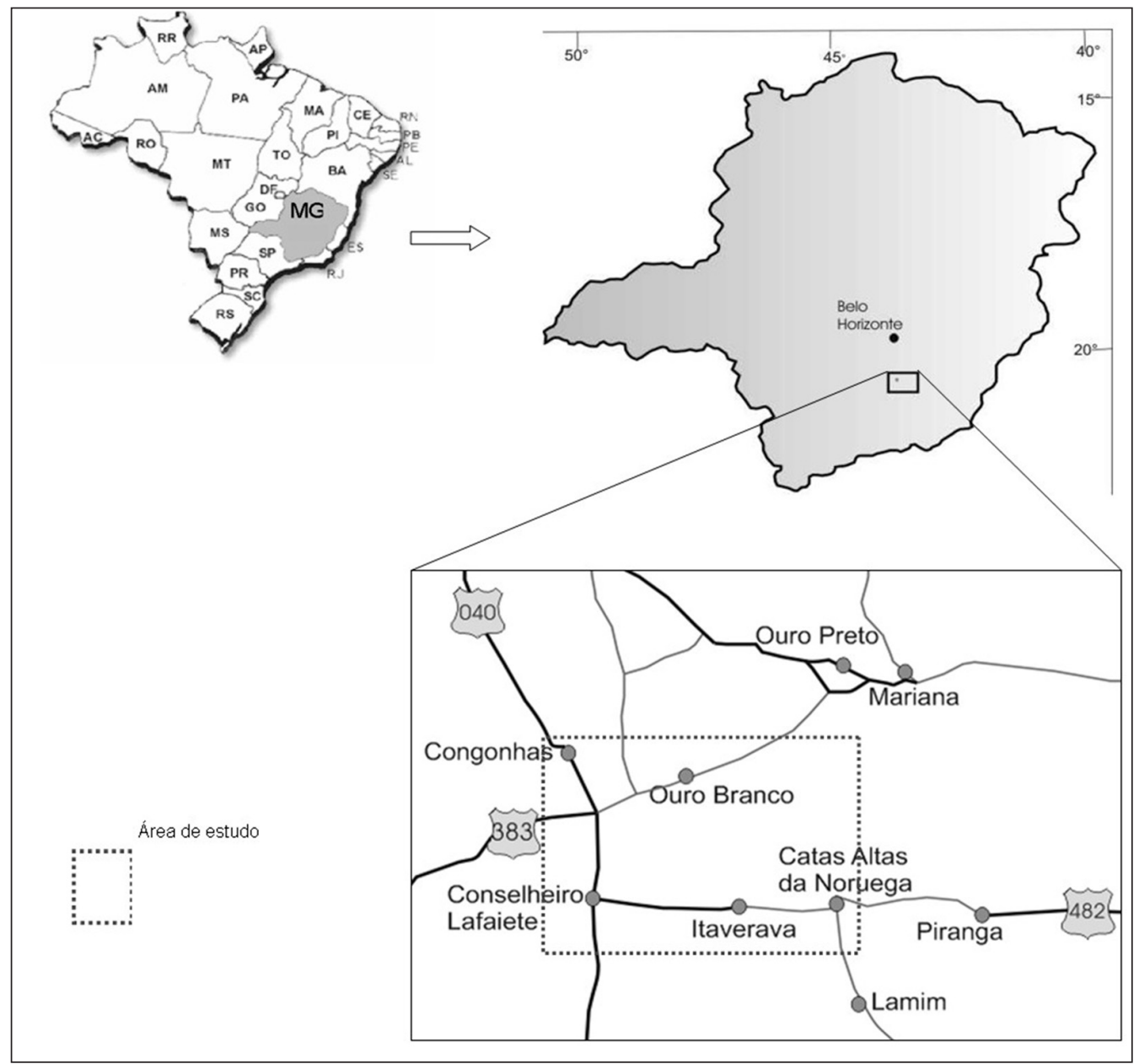

Figura 1 - Localização da área de estudo e vias de acesso. 


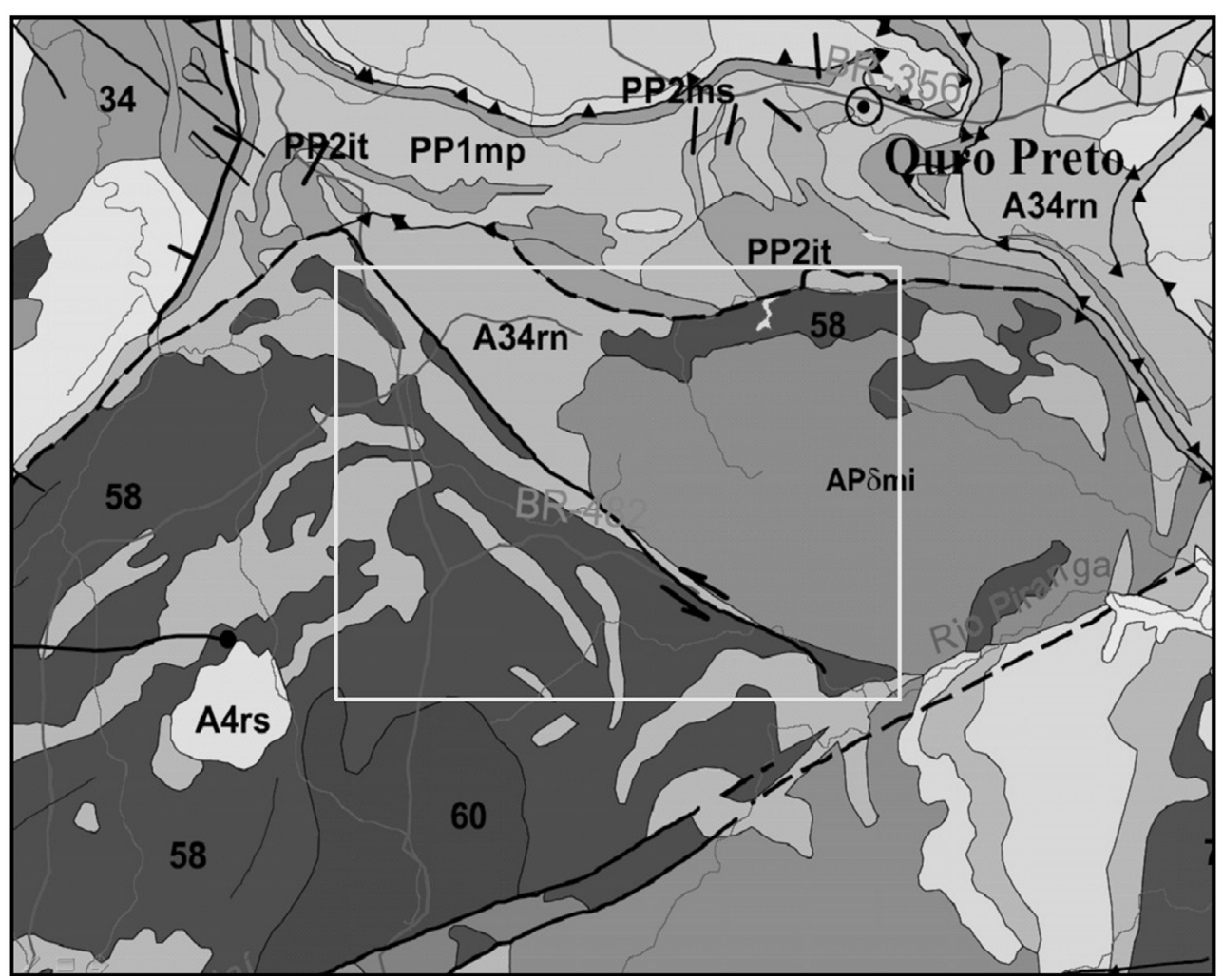

Figura 2 - Recorte do mapa geológico do Estado de Minas Gerais (COMIG 2003, escala 1:1.000.000). O retângulo circunscreve a área de estudo. Legenda: Legenda: $P R \gamma$ - Rochas granitóides. 58 - Alto Maranhão. 60 - Cupim. Pmi - Complexo Monsenhor Isidro. PP12m, PP1mp - Supergrupo Minas, Grupo Piracicaba. PP2it - Grupo Itacolomi. A4rs - Supergrupo Rio das Velhas, Grupo Maquine. A34rn Supergrupo Rio das Velhas, Grupo Nova Lima.

se apresenta sob a forma de faixas embutidas no embasamento granitóide-gnáissico. Na faixa Conselheiro Lafaiete-Congonhas, a seqüência do Grupo Nova Lima tem rochas ultramáficas komatíticas na base, sobrepostas por rochas máficas intercaladas com sedimentos e rochas ácidas a intermediárias com sedimentos alternados, no topo. A unidade ultramáfica da área possui composição peridotítica, com serpentinitos variados e os correspondentes produtos de alteração hidrotermal, que pode estar associada à alteração subaquosa, anterior à deformação penetrativa, ou pode ser correlacionada à circulação de fluidos durante o metamorfismo regional e à instalação de lineamentos de escala regional, tal como o Lineamento Congonhas.

O Granitóide Congonhas constitui-se de um corpo intrusivo, alongado no sentido N45W. Encontrase margeado por rochas supracrustais, majoritariamente da subunidade ultramáfica.

Os metassedimentos do Grupo Itacolomi (quartzitos, metaconglomerados e filitos, Dorr 1969), restringem-se a Serra do Ouro Branco. O filitos, xistos, quartzitos e dolomitos do Grupo Piracicaba (Dorr 1969) ocorrem somente no extremo Norte da área.

Rochas félsicas, máficas e ultramáficas milonitizadas caracterizam uma zona de transição entre as rochas supracrustais e gnaisses tonalíticos polideformados (Seixas 1988). Estes produtos milonitizados apre- sentam granulação fina, estrutura foliada, fitada a laminada, compostas de agregados quartzo-feldspáticos com porfiroclastos, alternados com domínios micáceos.

O Lineamento Congonhas - sítio de várias ocorrências auríferas, cuja gênese está estreitamente relacionada ao seu desenvolvimento - é a estrutura regional mais proeminente da área.

É caracterizado por uma foliação milonítica penetrativa, lineações e fraturas de dilatação.

A foliação milonítica do tipo S-C corresponde à estrutura mais eminente. Apresenta direção média N50W, com mergulhos verticais a 70NE (Seixas 1988).

Os vários indicadores cinemáticos sugerem que desenvolvimento do Lineamento Congonhas foi caracterizado por deslocamentos sinistrais policíclicos. Movimentos dextrais subordinados são interpretados como associados às acomodações de esforços tectônicos (Seixas 1988).

A superposição de movimentos transcorrentes e puros, evidenciados em milonitos da zona de maior deformação, sugere que a faixa afetada pelo Lineamento Congonhas representa uma zona de contato tectônico entre os gnaisses tonalíticos e as rochas supracrustais. Segundo a interpretação de Seixas (1988), falhas de empurrão foram responsáveis pelo transporte tectônico e justaposição destes conjuntos litológicos e, poste- 
riormente, foram reativadas na forma de falhamentos transcorrentes.

MATERIAIS E MÉTODOS Em síntese, o método empregado subdivide-se em três etapas de trabalho. A primeira refere-se ao estudo do modelo genético para definição do modelo prospectivo, a definição dos parâmetros a serem utilizados na análise e a compilação dos dados digitais pré-processados. A etapa subseqüente corresponde ao processamento dos dados, que diz respeito às diversas técnicas empregadas e avaliadas para o mapeamento de favorabilidade mineral. O último passo consiste na integração de dados e validação dos resultados e método propostos.

Modelo descritivo Análises geoquímicas de amostras em torno do Lineamento Congonhas evidenciaram que o metalotecto de maior potencialidade para mineralização aurífera na área corresponde à seqüência de rochas supracrustais (Seixas 1988). A seqüência é formada por duas associações litológicas principais (uma ígnea e uma sedimentar) que indicam um ambiente de transição entre rochas supracrustais da porção máfica-ultramáfica de greenstone belts e rochas vulcanossedimentares. Os metadoleritos, trondhjemitos e metaperidoritos talcificados e carbonatizados desta seqüência apresentam os maiores valores de concentração de ouro na área, juntamente com os metabasaltos. Ocorrem particularmente nas porções mais afetadas pela zona de cisalhamento do Lineamento Congonhas.

Devido às suas características, os metalotectos enquadram-se no modelo denominado depósitos de ouro do tipo lode (Seixas 1988, Hutchinson 1987, Groves et al. 1987, Hodgson 1985 e 1993), sendo fortemente condicionados pela instalação da estrutura de cisalhamento. Segundo o modelo proposto por Hodgson (1993), tais depósitos caracterizam-se por constituírem depósitos exclusivamente de $\mathrm{Au}$, nos quais a maior parte das zonas mineralizadas é asociada a estruturas, tais como falhas de grande escala, zonas de cisalhamento dúcteis ou fraturas rúpteis de alto ângulo. Freqüentemente, as estruturas nas quais ocorrem as mineralizações estão associadas a contatos entre domínios litológicos contrastantes, marcados por rochas deformadas ou indicadas indiretamente por uma variedade de feições - discordâncias estruturais, zonas de alteração hidrotermal ricas em carbonatos, entre outras.

A razão pelos quais os depósitos de ouro do tipo lode se relacionam a grandes falhas reside no fato destas agirem como eficientes condutos de fluidos hidrotermais. As mineralizações, em geral, concentram-se nas ramificações (splays) das estruturas, que apresentam uma geometria complexa - favorável à dilatação e à circulação dos fluidos.

A maioria dos depósitos conhecidos de ouro do tipo lode situa-se em cinturões caracterizados pela conjunção de três assembléias litológicas: rochas vulcânicas (komatiíticas) e intrusivas máficas a ultramáficas com elevado teor de $\mathrm{Mg}$; faixas de rochas sedimentares; e intrusões félsicas. Vale destacar que todas estas condicionantes ocorrem na área de estudo.

Seleção dos parâmetros geofísicos Áreas afetadas por processos hidrotermais, em especial associadas a zonas de cisalhamento, hospedam um grande número de depósitos minerais e, por esta razão, têm sido estudadas e exploradas em diversas regiões do mundo, inclusive através de levantamentos aerogeofísicos. Dados magnetométricos têm sido amplamente empregados na prospecção de ouro devido à associação de grande número de depósitos auríferos arqueanos e proterozóicos à formações ferríferas bandadas, sedimentos metamorfizados ricos em $\mathrm{Fe}$ e/ou rochas vulcânicas básicas a ultrabásicas, litotipos estes geralmente magnéticos (Boyd 1984). Assim, a magnetometria fornece evidências indiretas sobre as mineralizações auríferas através de características das rochas hospedeiras às quais se associam.

A utilização de dados gamaespectrométricos justifica-se pelo fato dos fluidos hidrotermais serem ricos em diversos cátions e ânions, dentre eles os cátions de ${ }^{39} \mathrm{~K}$, bem como de seu radioisótopo ${ }^{40} \mathrm{~K}$.

$\mathrm{O}$ isótopo ${ }^{40} \mathrm{~K}$ é responsável por aproximadamente 98\% da emissão de radiação gama de radioisótopos primários presentes na crosta terrestre. Tal aspecto torna viável e conveniente a utilização de dados aerogamaespectrométricos visando ao reconhecimento de zonas alteradas por hidrotermalismo (em específico, potassificação), às quais podem estar associados importantes depósitos minerais (Adams \& Gasparini 1967, Pires 1995, Quadros et al. 2003).

Além do enriquecimento em potássio, as áreas submetidas à intensa alteração hidrotermal podem apresentar um empobrecimento na concentração do elemento tório (Quadros et al. 2003).

Tais características nortearam a definição dos parâmetros a serem utilizados no estudo de favorabilidade mineral.

\section{Constituição da base e processamento dos dados} DADOS DE OCORRENCIAS MINERAIS Um mapa atualizado de ocorrências minerais foi obtido junto à CPRM, contendo informações sobre a localização geográfica das ocorrências, substâncias primárias e secundárias, rocha hospedeira, rocha encaixante, tipo de alteração associada, entre outros atributos associados a cada ocorrência mineral. Dentre os diversos bens minerais apresentados, utilizaram-se apenas as informações referentes às ocorrências de ouro da área investigada.

DADOS AEROGEOFÍSICOS A base de dados aerogeofísicos (magnetométricos e gamaespectrométricos) utilizados foi gerada a partir de dados do Projeto Pitangui-São João Del Rey-Ipatinga, que corresponde à Área 2 do Programa de Levantamento Aerogeofísico do governo de Minas Gerais (Lasa 2001). O levantamento foi executado com sobrevôo a $100 \mathrm{~m}$ de altura segundo linhas espaçadas de $250 \mathrm{~m}$, com linhas de controle a cada 2.500 m e direções de linha de vôo de N30W (Bloco Leste) e N30E (Bloco Oeste). O magnetômetro, com 
resolução de $0,001 \mathrm{nT}$, permitiu obtenção de leituras a cada 8 metros no terreno. O gamaespectrômetro, com 256 canais espectrais para a determinação dos fotopicos de potássio $\left({ }^{40} \mathrm{~K}\right)$, urânio $\left({ }^{238} \mathrm{U}\right)$ e tório $\left({ }^{232} \mathrm{Th}\right)$ permitiu a obtenção de dados a cada 80 metros do terreno. Diversas rotinas de pré-processamento foram conduzidas pela empresa responsável pelo Levantamento (remoção da variação magnética diurna, correção do erro de paralaxe, nivelamento e micronivelamento, caso dos dados magnéticos, e correção de tempo morto, filtragem linear e passa-baixa, remoção do background, correção do efeito Compton e correção altimétrica para dados gamaespectrométricos) (Lasa 2001). No âmbito do projeto, a primeira etapa de pré-processamento iniciou-se com a verificação da sobreposição de linhas de vôo. Em seguida, analisou-se a presença de inconsistências, a distribuição espacial e a densidade de amostragem.

Devido aos ruídos remanescentes do nivelamento convencional e associados às imperfeições do nivelamento das malhas após a interpolação, procedese ao micronivelamento (Minty 1991), que corresponde à aplicação de filtros que podem reduzir ou até excluir estas altas freqüências indesejáveis.

O próximo passo consistiu na interpolação da base de dado. $\mathrm{O}$ tamanho das células da grade foi estabelecido em 100 metros, utilizando-se o método da curvatura mínima, com interações e ângulos de inclinação e declinação para a geração dos grids sombreados de $45^{\circ}$. Foram criadas diversas cartas-imagem - amplitude do sinal analítico, gradiente horizontal total do campo magnético anômalo, derivada vertical do campo magnético anômalo e um mapa e estruturas geológicas interpretadas a partir dos dois últimos (Fig. 3) -, a partir das quais se determinaram mapas evidenciais utilizados para a subseqüente geração de mapas de favorabilidade mineral.

Os dados gamaespectrométricos foram micronivelados e interpolados de maneira análoga ao préprocessamento de dados magnetométricos. Avaliou-se a influência do relevo sobre a distribuição dos elementos através do modelo digital de elevação, gerado com dados do SRTM (Shuttle Radar Topography Mission) (Souza Filho, 2003). Na porção N-NW da área de estudo, ruídos intensos são decorrentes das elevadas alturas de sobrevôo condicionadas pela Serra de Ouro Branco. Manifestam-se como valores elevados de U e baixos de $\mathrm{K}$. De modo geral, as modelagens conduzidas no âmbito deste trabalho não foram prejudicadas pela presença destas inconsistências, mas vale reservar cautela quando da interpretação dos resultados referentes a tal porção. Geraram-se diversos produtos a partir dos dados processados, dentre os quais se destacam composições em falsa cor (Killeen, 1979) e combinações ternárias (RGB e CMY), na qual se combinam os três canais espectrométricos (K, Th e $\mathrm{U})$, com as três cores primárias aditivas (vermelho, verde e azul) (Fig. 4). Dentre os produtos mais interessantes para as etapas seguintes de processamento e avaliação, destaca-se o mapa da razão entre os elementos $\mathrm{K}$ e Th, o qual evidencia áreas concomitantemente enriquecidas em $\mathrm{K}$ e empobrecidas em Th (Fig. 4).

Dados de sensores remotos Foram utilizadas cenas dos sensores orbitais Terra/ASTER, Landsat7/ETM+e SRTM. O pré-processamento das imagens envolveu redimensionamento dos pixels para 15 metros, de modo a torná-los compatíveis com os dados geofísicos. A partir das cenas de cada sensor, foram criados os mosaicos que recobrem a área investigada. Foram empregadas as bandas AST3, 2 ,1 e ETM4,3,2 em composições RGB dos mosaicos dos sensores ASTER e ETM+, respectivamente, para a cartografia de lineamentos (Fig. 5).

\section{Processamento Digital}

REALCE POR TECNICAS CONVENCIONAIS Os métodos de classificação não-supervisionada, tais como ISODATA (Iterative Self-Organizing Data Analysis Technique) e Média-K, baseiam-se no tratamento estatístico dos dados e podem ser aplicados para qualquer tipo de imagem. Utiliza-se tal classificação quando se deseja evitar influência do conhecimento prévio nos resultados a serem obtidos. Consistem, resumidamente, em um processo no qual todos os pixels de uma imagem que possuam assinaturas semelhantes são identificados e agrupados em múltiplas categorias pelo software. No processo, agrupamentos de dados são automaticamente identificados e utilizados como áreas de treinamento para a classificação.

O resultado mais satisfatório da técnica ISODATA foi obtido utilizando-se dados geofísicos (canais de K, Th e U e amplitude do sinal analítico) (Fig. 6), no qual é possível reconhecer domínios geofísicos, diretamente correlacionáveis com unidades litológicas do mapa geológico regional.

CLASSIFICAÇÃO SUPERVISIONADA Na análise de dados guiada pelo conhecimento, ou knowledge-driven, os pesos dos mapas evidenciais utilizados para a obtenção de mapas de favorabilidade são atribuídos com base na experiência do profissional (Bonham-Carter 1994). Foram aplicadas aos dados geofísicos técnicas de classificação baseadas nas lógicas booleana e fuzzy, no ambiente de um sistema de informações georreferenciadas.

A análise booleana baseia-se na combinação lógica de mapas binários por operadores lógicos (AND OR x OR) visando validar uma hipótese - neste caso, se determinada área é favorável para a presença de ocorrência de mineralizações de ouro do tipo lode.

Os mapas são obtidos após a conversão das informações de diferentes mapas condicionantes para um formato binário (verdadeiro ou falso, que correspondem a dois estados: prospectivo e não-prospectivo, respectivamente) (Knox-Robinson \& Groves 1997). Obtémse um mapa final também no formato binário, no qual há, portanto, apenas duas classes: uma correspondente a todas as condições dos diferentes mapas satisfeitas, e outra se uma ou mais condições não forem satisfeitas (Bonham-Carter 1994).

Esta característica torna a análise booleana 


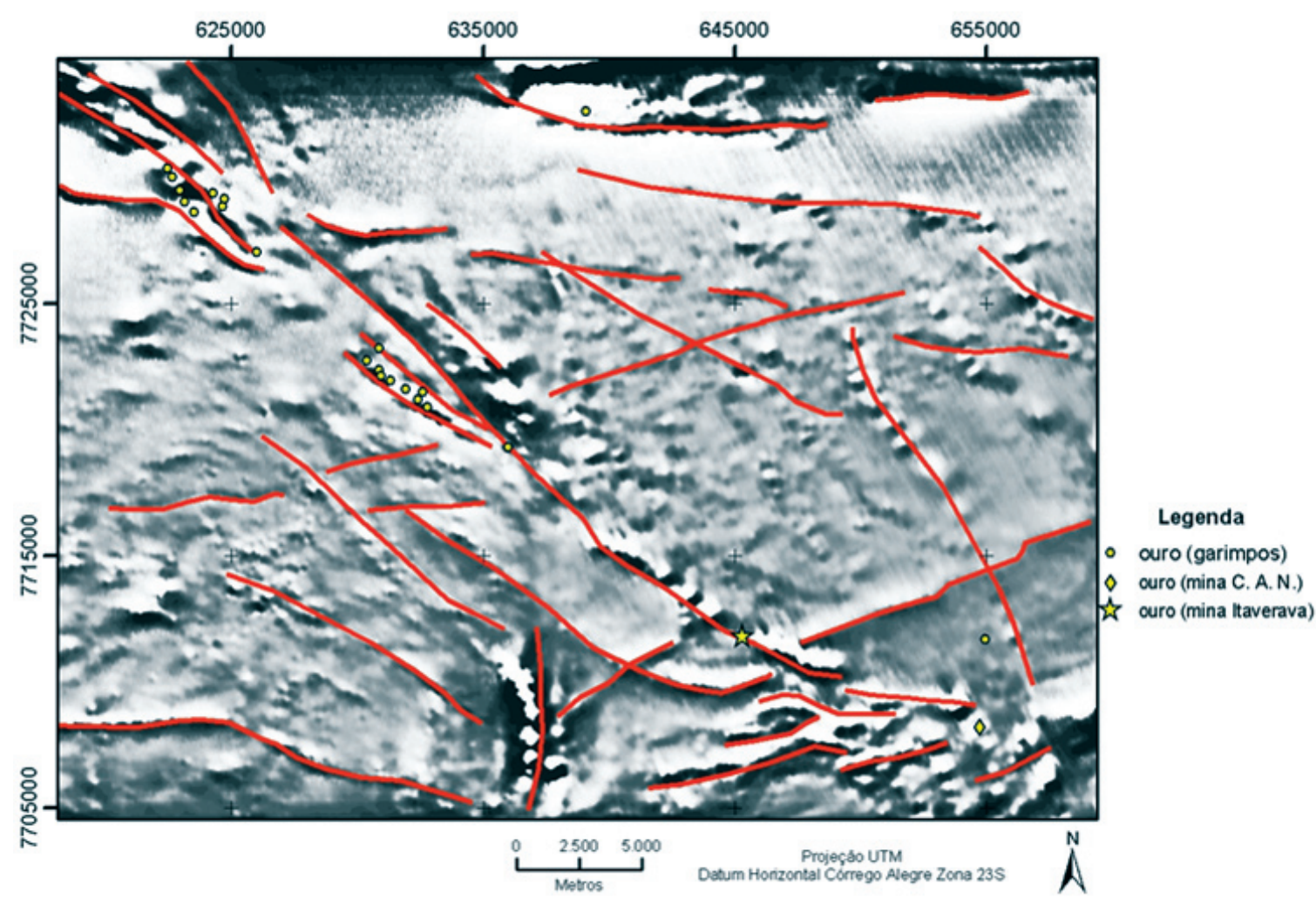

Figura 3 - Mapa de lineamentos associados a estruturas geológicas observáveis nos produtos magnetométricos (derivada vertical e gradiente horizontal total do campo magnético anômalo) sobreposto ao mapa da derivada vertical. (imagem colorida disponivel na versão on-line)

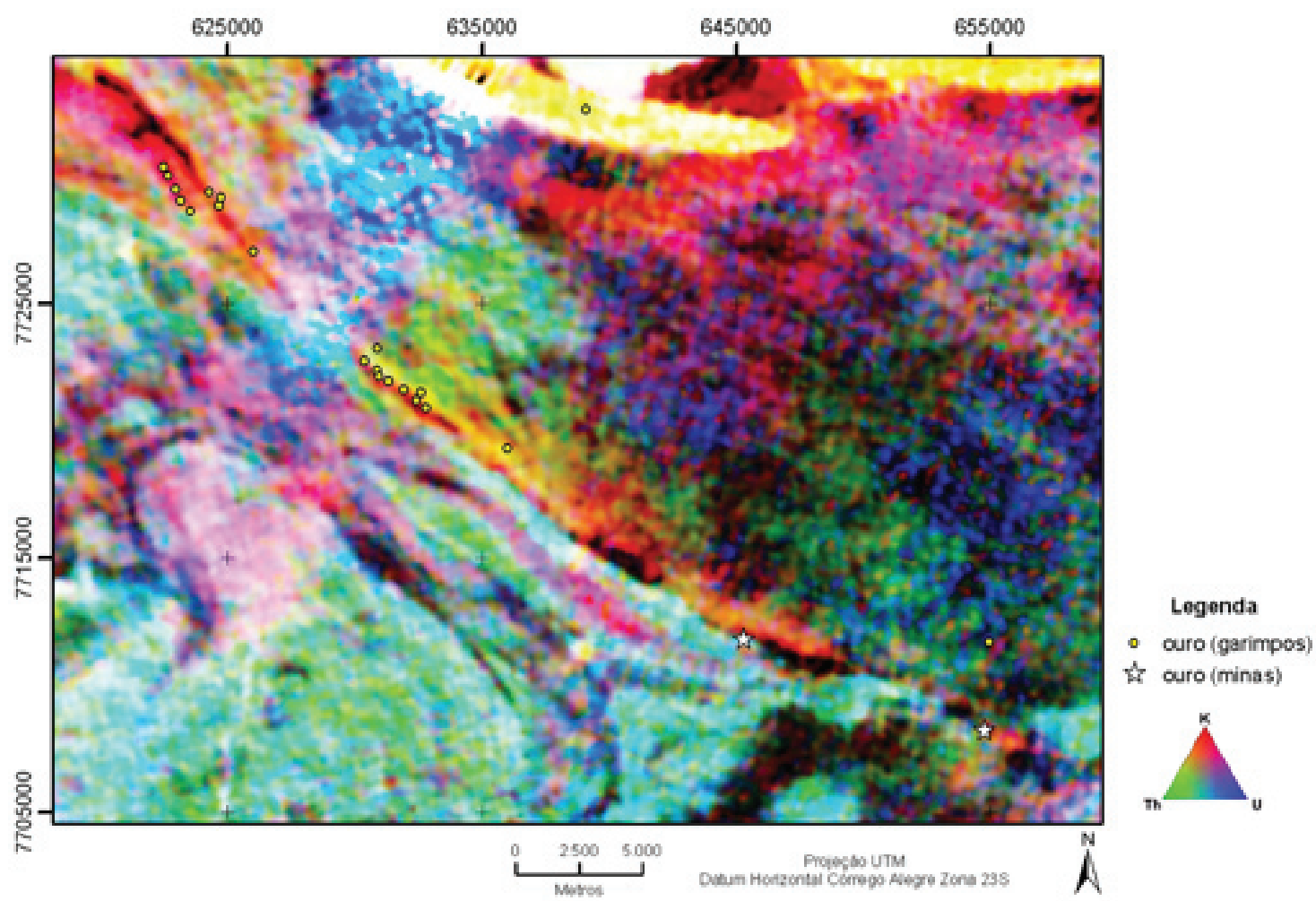

Figura 4a - Mapas gamaespectrométricos ternário dos canais de K, The U (composição RGB). (imagem colorida disponível na versão on-line) 


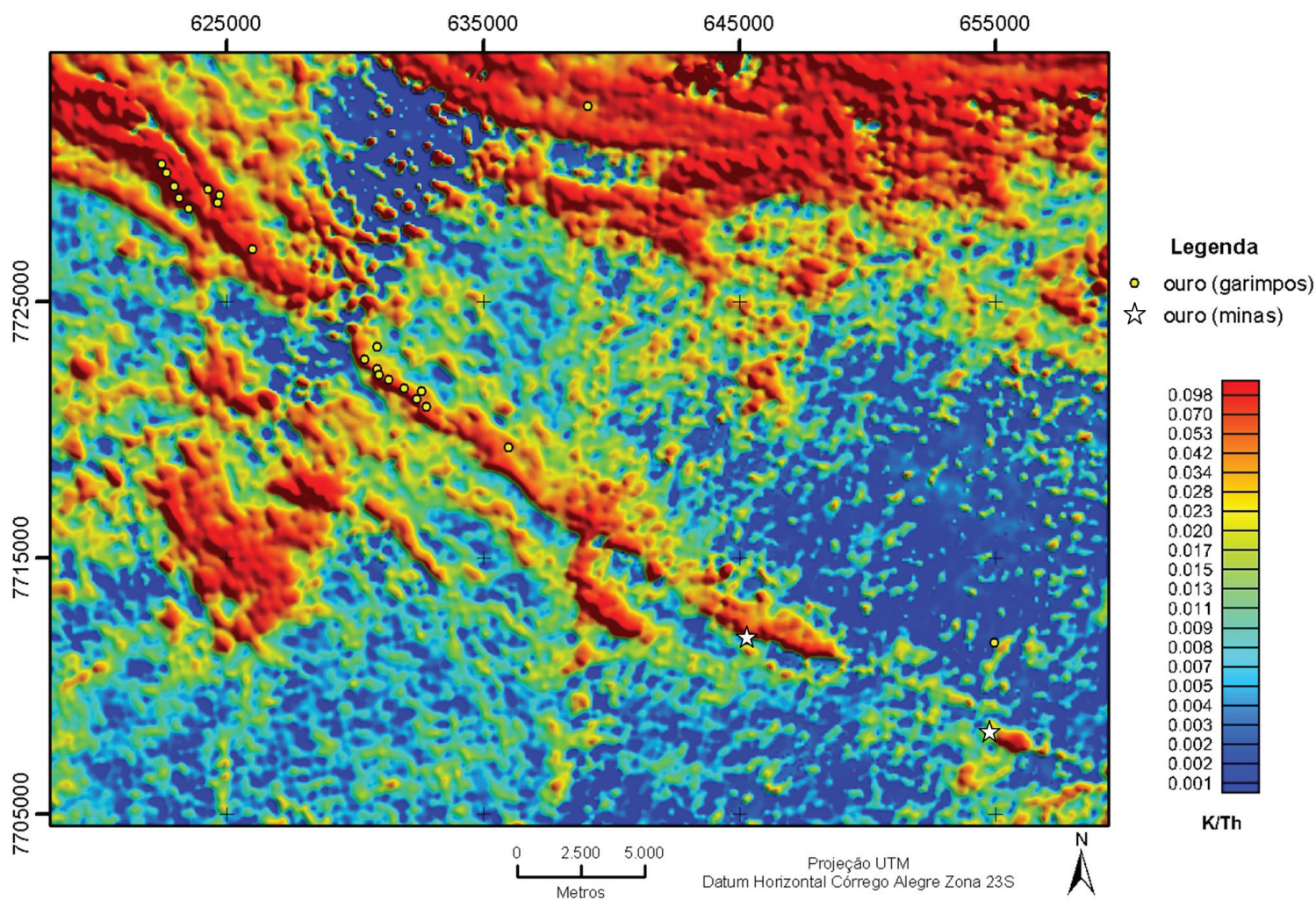

Figura $4 b$ - Mapas gamaespectrométricos com pseudocor da razão K/Th. (imagem colorida disponivel na versão on-line)

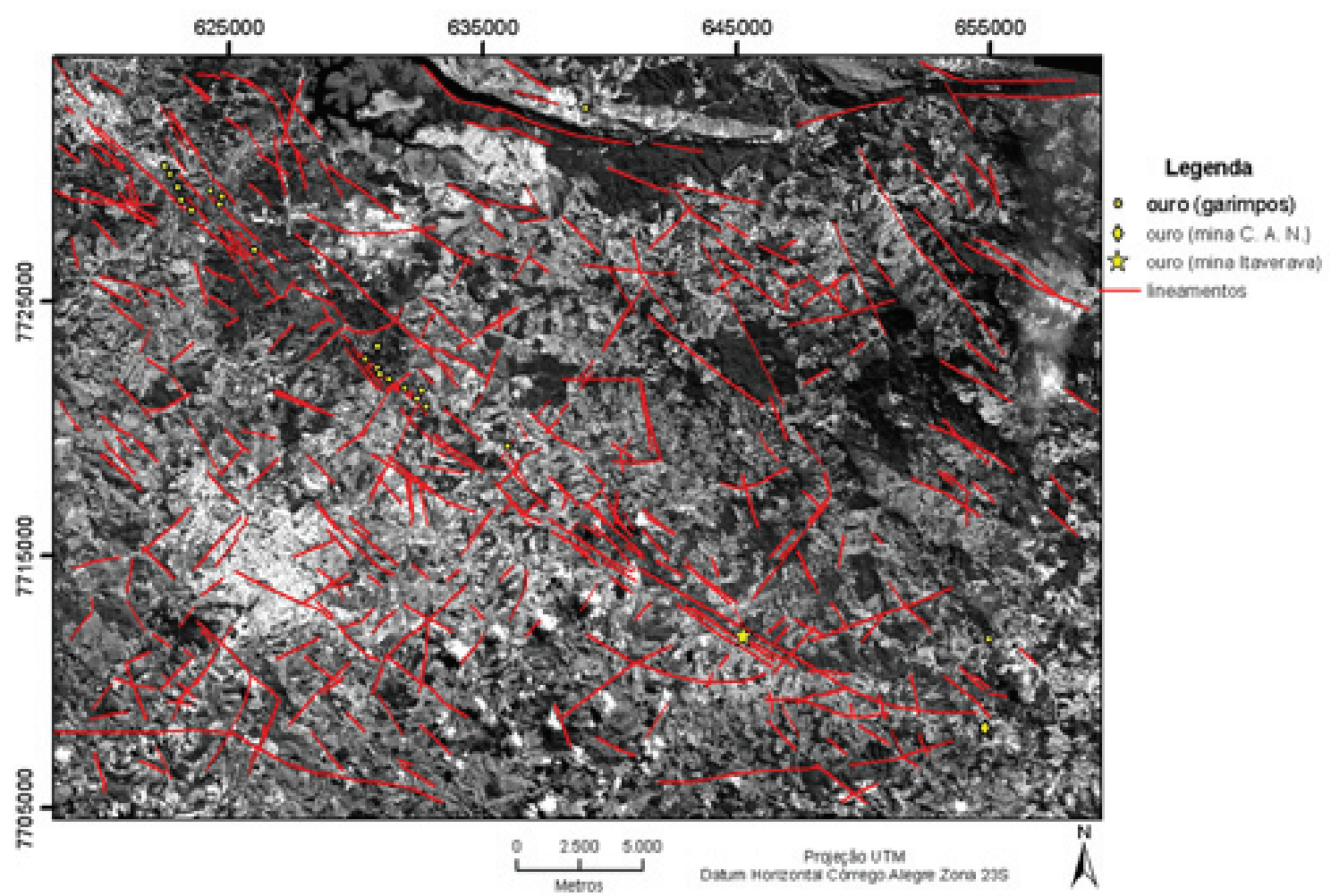

Figura 5 - Mapa de lineamentos interpretados a partir das imagens dos sensores ASTER e ETM+, sobreposto à banda 1 do ASTER. (imagem colorida disponível na versão on-line)

pouco conveniente no estudo de favorabilidade mineral, visto que são excluídas possíveis áreas de interesse em função de uma condição não ser cumprida. Uma alternativa para contornar essa limitação 
é o método Index Overlay (Bonham-Carter 1994), cuja vantagem consiste na atribuição de diferentes pesos para cada mapa de evidência, dependendo do significado e da importância do mesmo em relação à hipótese considerada.

Os mapas evidenciais, em formato binário, utilizados na análise booleana foram os mapas gamaespectrométricos (canais de $\mathrm{K}$, Th e $\mathrm{U}$ ) e magnetométricos (amplitude do sinal analítico), bem como um mapa temático de zonas (buffers) ao redor das principais estruturas geológicas (interpretadas a partir dos mapas de gradiente horizontal total e derivada vertical do campo magnético anômalo e do mosaico do sensor ASTER). Assim, assinalou-se valor 1 às áreas enriquecidas em $\mathrm{K}$, empobrecidas em U e Th, de elevada susceptibilidade magnética e distantes até $700 \mathrm{~m}$ das estruturas. Às áreas que não atendem estas exigências foi conferido o valor zero. Os resultados mais interessantes correspondem ao produto booleano e ao index overlay, no qual classificam-se as áreas de mais alta favorabilidade para mineralizações de ouro do tipo lode (vermelho) até de baixa favorabilidade (azul claro), dependendo do número de condicionantes satisfeitos (Fig. 7).

A pertinência de dados sob a ótica da lógica $f u$ $z z y$, diferentemente da booleana, é expressa em termos de uma escala contínua que abrange todos os valores contidos entre 0 e 1 , onde 0 representa não-pertinência total (full non-membership) e 1, pertinência total (full membership). Entre estes extremos, há uma faixa de possíveis valores de pertinência.

Diversos mapas evidenciais podem ser combinados entre si através de diferentes operadores ("e fuzzy", "ou fuzzy", "produto algébrico fuzzy", "soma algébrica fuzzy" e "operador fuzzy gama"), cada qual apresentando vantagens e/ou desvantagens. $\mathrm{O}$ resultado mais interessante corresponde ao "operador fuzzy gama" (Bonham-Carter 1994), que possibilita contornar e contrabalancear o efeito minimizante do "produto algébrico fuzzy" e o efeito maximizante da "soma algébrica fuzzy". Este operador é definido pela seguinte equação:

\section{operador fuzzy gama $=(\text { soma algébrica } f u z z y)^{\gamma} \mathrm{x}$ (produto algébrico fuzzy) ${ }^{1-\gamma}$,}

no qual $\gamma$ corresponde a um parâmetro escolhido no intervalo de 0 a 1 (Zimmermann \& Zysno 1980). A escolha do valor de $\gamma$ cabe ao especialista e deve ser função da resposta que este espera obter dos dados.

$\mathrm{O}$ processamento dos dados para a análise $f u$ zzy consistiu na reclassificação dos mapas $(\mathrm{K}, \mathrm{Th}, \mathrm{U}$, ASA e estruturas geológicas) para 25 classes. A cada uma delas foram atribuídos, subjetivamente, os valores de pertinência fuzzy (fuzzy membership). Assim, à classe correspondente aos mais altos valores de $\mathrm{K}$ foi conferida pertinência fuzzy 1, à classe subseqüente foi assinalado o valor 0,95 e assim por diante, até as áreas com os mais baixos valores de $\mathrm{K}$, que receberam valor de pertinência 0 . Analogamente, definiu-se os valores para o mapa de amplitude do sinal analítico. De modo inverso, foram processados os mapas de U e Th (baixos valores dos elementos, alto valor de pertinência, e vice versa).

Buffers de 200 metros foram gerados ao redor das estruturas geológicas principais, ponderados de forma que a zona mais próxima mostra maior afinidade em mapear alvos favoráveis (valor 1 - função da influência de fluidos hidrotermais canalizados ao longo das estruturas), e aos mais distantes (até 1000 metros) são atribuídas pertinências sucessivamente menores.

O resultado do "produto algébrico fuzzy" (Fig. 8a) é bastante restritivo, de modo que as áreas destacadas como de alta favorabilidade possuem altos valores de pertinência fuzzy em todos mapas evidenciais (áreas destacadas em vermelho).

O mapa de favorabilidade para ouro do tipo lode resultante da análise pelo "operador fuzzy gama" corresponde ao produto mais importante (Fig. 8b), por destacar bem áreas que coincidem com ocorrências auríferas já cartografadas. $\mathrm{O}$ valor do operador foi definido como $\gamma=0,7$.

\section{CLASSIFICAÇÃO SUPERVISIONADA DE DADOS} AEROGEOFISICOS COM BASE NOS ALGORITMOS SPECTRAL ANGLE MAPPER E MIXTURE TUNED MATCHED FILTERING A classificação supervisionada é empregada quando já se têm informações sobre dados de interesse da imagem, a partir dos quais se especifica classes de interesse. O processo de classificação supervisionada procura, então, por todos os pixels com características espectrais ou geofísicas semelhantes.

Dois métodos de classificação supervisionada, o Spectral Angle Mapper (SAM) (Kruse et al. 1993) e o Mixture Tuned Matched Filtering (MTMF) (Boardman et al. 1995), originalmente concebidos para classificação espectral de imagens hiperespectrais de sensoriamento remoto, foram aplicados e testados com dados aerogeofísicos. O objetivo foi mapear as assinaturas magnéticas e gamaespectrométricas dos litotipos e estruturas aos quais se associam as ocorrências e as minas de ouro da área de estudo. Ambos fundamentam-se na comparação entre a assinatura dos pixels de composição desconhecida que integram a imagem, e a assinatura dos pixels de referência, previamente determinados como alvos ou endmembers, associados às ocorrências de ouro já conhecidas da área.

Aplicaram-se as técnicas para duas imagens uma composta por oito bandas dos dados gamaespectrométricos ( $\mathrm{U}, \mathrm{Th}, \mathrm{K}$ e razões entre estes isótopos: $\mathrm{K} /$ Th, K/U, U/Th, U/K e Th/K) e outra formada por quatro bandas, incluindo dados magnetométricos $(\mathrm{K}, \mathrm{Th}, \mathrm{U}$ e amplitude do sinal analítico).

Spectral Angle Mapper (SAM) O SAM consiste em uma técnica empregada para comparar uma propriedade (espectro, composição química, etc.) de cada pixel de uma imagem com propriedades individuais (espectros de bibliotecas espectrais, composições químicas predeterminadas, etc.), com base em uma medida de 


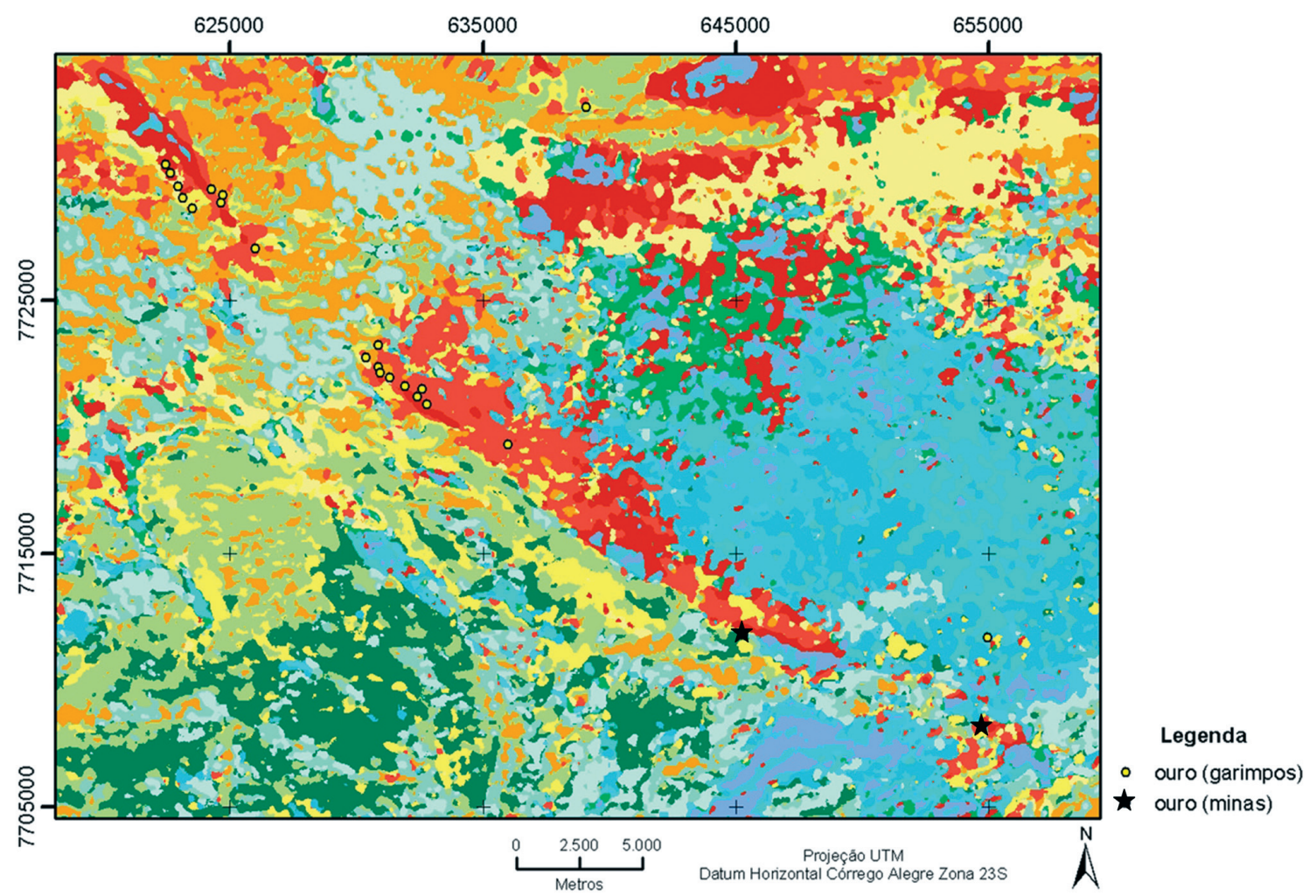

Figura 6 - Mapa de classificação não-supervisionada do tipo ISODATA dos dados gamaespectrométricos (canais de $K$, The U) e magnetométricos (amplitude do sinal analítico). Número de classes $=15$. Número de interações $=10$. Desvio padrão $=1,0$. (imagem colorida disponível na versão on-line)

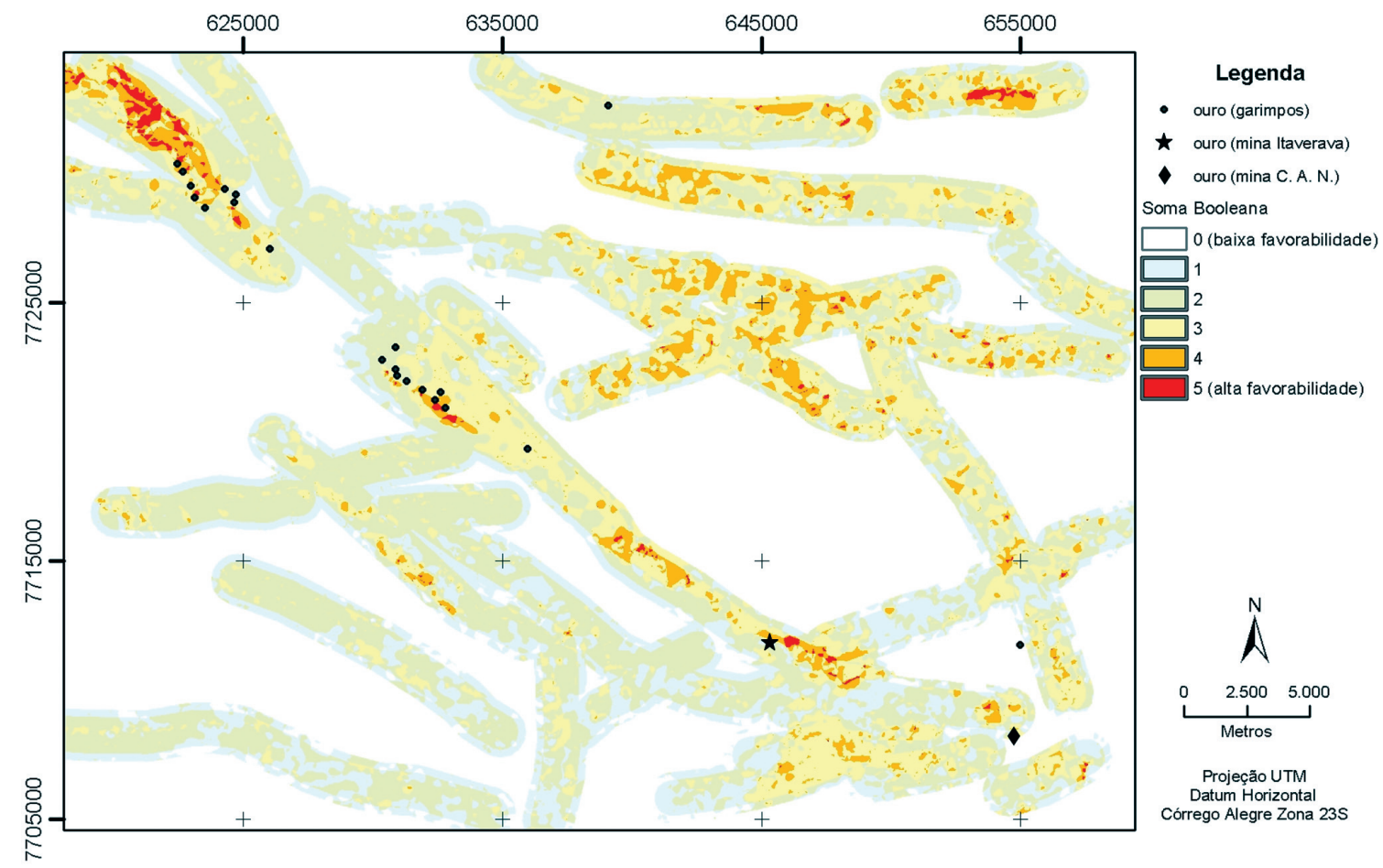

Figura 7 - Mapa de favorabilidade para mineralizações de ouro segundo análise booleana (index overlay). Classe $5=$ todos condicionantes satisfeitos; classe $0=$ nenhum condicionante satisfeito. (imagem colorida disponível na versão on-line) 
similaridade, designada de ângulo espectral (Kruse et al. 1993).

As características entre pixels tomados como de referência (de assinatura conhecida) e o restante dos pixels da imagem (de assinatura desconhecida) são consideradas como vetores. Quanto maior a similaridade entre estes pixels, menor o ângulo entre os dois vetores.

A aplicação da técnica resulta em dois produ- tos: um mapa de classes e imagens rule, nas quais os pixels correspondem ao ângulo espectral. Como os pixels claros nestas imagens correspondem a ângulos grandes e, portanto, de menor interesse, enquanto ângulos pequenos, associados à maior similaridade entre os pixels de referência e os demais, são representados por pixels escuros, invertem-se seus histogramas, por uma questão visual. Deste modo, atribuem-se aos melhores
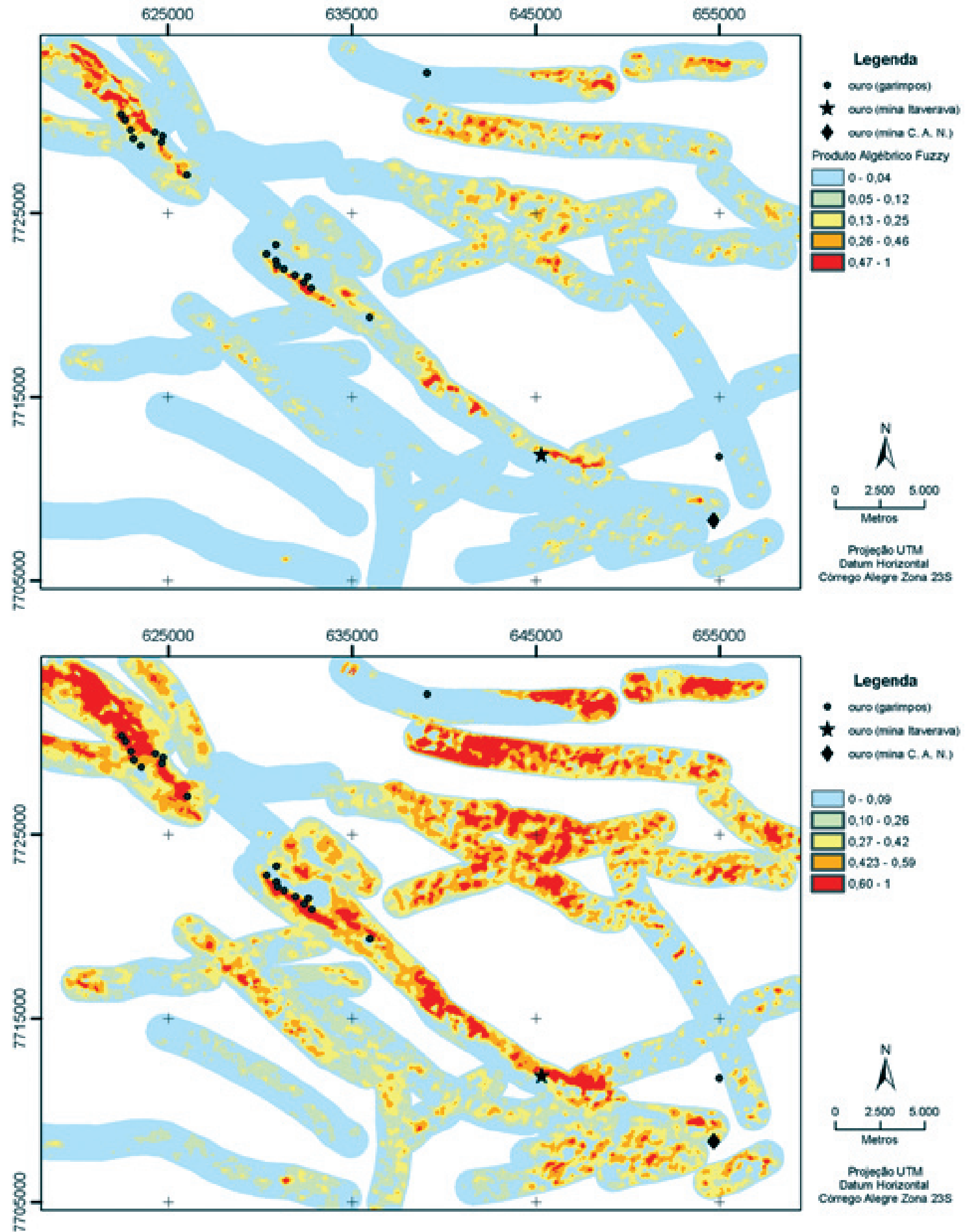

Figura 8 - Mapas de favorabilidade para mineralizações de ouro do tipo lode (a) (superior) segundo análise fuzzy (produto algébrico fuzzy) ; b) (inferior) segundo análise fuzzy (operador $\gamma=0,7)$. Baixos valores de pertinência fuzzy = áreas pouco prospectivas; altos valores = áreas prospectivas. (imagem colorida disponível na versão on-line) 
resultados pixels claros e aos resultados de menor interesse pixels escuros.

No intuito de isolar a informação de maior interesse, seus histogramas ainda devem ser criteriosamente ajustados, destacando apenas pixels associados a um intervalo pequeno de valores de ângulo.

Três categorias de pontos de treinamento foram definidas - uma referente às garimpos de ouro e duas outras relativas às minas de ouro (de Catas Altas da Noruega e Itaverava). Estes pixels de referência, associados às ocorrências de ouro, foram utilizados para a determinação da similaridade com os demais. O pósprocessamento consistiu da filtragem das classes, de modo a agrupar os pixels e eliminar aqueles dispersos na imagem.

Os mapas resultantes das duas técnicas revelam similaridades na distribuição de três alvos, associados a cada uma das três classes de treinamento (garimpos, mina de Itaverava e mina de Catas Altas da Noruega) (Fig. 9).

O alvo 1, classe gerada a partir dos pontos de treinamento associados aos garimpos de ouro, relaciona-se estreitamente ao Lineamento Congonhas. Já o alvo 2, associado à mina de Itaverava, apresenta uma distribuição mais ampla, com diversos pixels selecionados na porção Sudeste da área, enquanto o alvo 3, cujo ponto de treinamento é a mina de Catas Altas da Noruega, ocorre majoritariamente na porção central e Nordeste da área.

Mixture Tuned Matched Filtering (MTMF) A técnica MTMF utiliza-se de um filtro de ajuste para maximizar a resposta do endmember a ser mapeado à escala de sub-pixel (Chen \& Reed 1987). O bloco Matched Filtering (MF) do algoritmo produz imagens de endmembers, denominadas MF Scores, cujos valores variam de 0 a 1 quanto mais próximos de 1 forem os resultados, maior a dominância da assinatura de determinado endmember no pixel analisado (p.ex: um pixel com valor de 0.9 (MFS) é interpretado como sendo composto por $90 \%$ do endmember). O problema do MF é a geração de um grande número de falsos positivos. O bloco Mixture Tuned (MT) do algoritmo visa justamente à minimização dos falsos positivos, através do cálculo de um parâmetro denominado improbabilidade (infeasibility). Nesse caso, os pixels com maior possibilidade de conterem a assinatura de um endmember particular são determinados em um diagrama de dispersão bidimensional, no qual são selecionados os pixels que possuam valores de Matched Filter Score acima de zero e mais próximos de 1, e baixa improbabilidade. As áreas que apresentam boa correlação com os endmembers são destacadas na imagem.

Determinou-se a assinatura geofísica dos litotipos e estruturas às quais se associam as ocorrências auríferas, através da técnica MTMF, utilizando-se os canais de $\mathrm{K}$, Th e U, bem como os dados de amplitude do sinal analítico.

Os pontos de treinamento (pixels associados aos garimpos de ouro e às minas de Itaverava e Catas Altas da Noruega) foram considerados endmembers, cujas assinaturas foram analisadas para os pixels da imagem através do classificador MTMF. Através dos respectivos gráficos de dispersão, os pixels com alto valor de Score e baixo valor de improbabilidade foram considerados como mapeados corretamente e destacados nos mapas correspondentes (Fig. 10).

Análise por Principais Componentes (APC) A principal característica da APC é determinar a extensão da correlação entre bandas e separá-la através de uma transformação matemática (Drury 2001). A correlação entre bandas obscurece diferenças sutis entre a composição dos materiais, dificultando sua distinção, além de implicar em redundância de dados.

$\mathrm{Na}$ APC, analisam-se a correlação entre $n$ imagens brutas e produz-se um novo conjunto de $n$ imagens não-correlacionadas. A primeira destas novas imagens, denominada de PC1 (Principal Componente 1), contém informações comuns a todas $n$ bandas originais; a segunda imagem (PC2) concentra a feição espectral mais significante do conjunto e, assim por diante, até a última PC, a qual conterá a informação restante (não qualitativamente inferior, apenas quantitativamente menor) (Drury 2001).

No processo da APC, obtém-se uma matriz de autovetores que, quando convertida para valores em porcentagens, fornece a contribuição de cada banda original na formação de cada uma das PCs. Define-se, então, em qual PC se concentra a informação espectral ou geofísica de interesse.

A APC foi aplicada aos dados aerogeofísicos (canais de U, Th, K e amplitude do sinal analítico ASA). Selecionou-se a PC que apresenta os menores índices de autovalores para os canais de K e ASA, e maiores índices para os canais de U e Th. Para que seja possível determinar áreas favoráveis à mineralização aurífera do tipo lode, procede-se à inversão do histograma, de maneira a se obter uma imagem com pixels brancos representando contribuição majoritária das bandas da ASA e do K e pixels escuros evidenciando reduzida contribuição dos canais de Th e U. O ajuste fino do histograma ainda permite destacar as áreas mais prospectivas do background no produto final (Fig. 11), no qual as áreas assinaladas como de maior favorabilidade a mineralização de ouro se concentram ao longo da zona de cisalhamento, devido ao enriquecimento em $\mathrm{K}$ e da alta susceptibilidade magnética que as rochas nas proximidades da mesma apresentam.

\section{INTEGRAÇÃO E DISCUSSÃO DOS RESULTA-}

DOS O Lineamento Congonhas é definido, em diversos produtos gerados, em função das propriedades das rochas que afeta. Assim, destaca-se pelas anomalias positivas de $\mathrm{K}$ e da amplitude do sinal analítico e pelas baixas concentrações de $\mathrm{Th}$ - características estas diretamente relacionadas à percolação de fluidos e à decorrente alteração hidrotermal às quais as rochas foram submetidas.

À exceção de duas, todas as ocorrências de ouro 


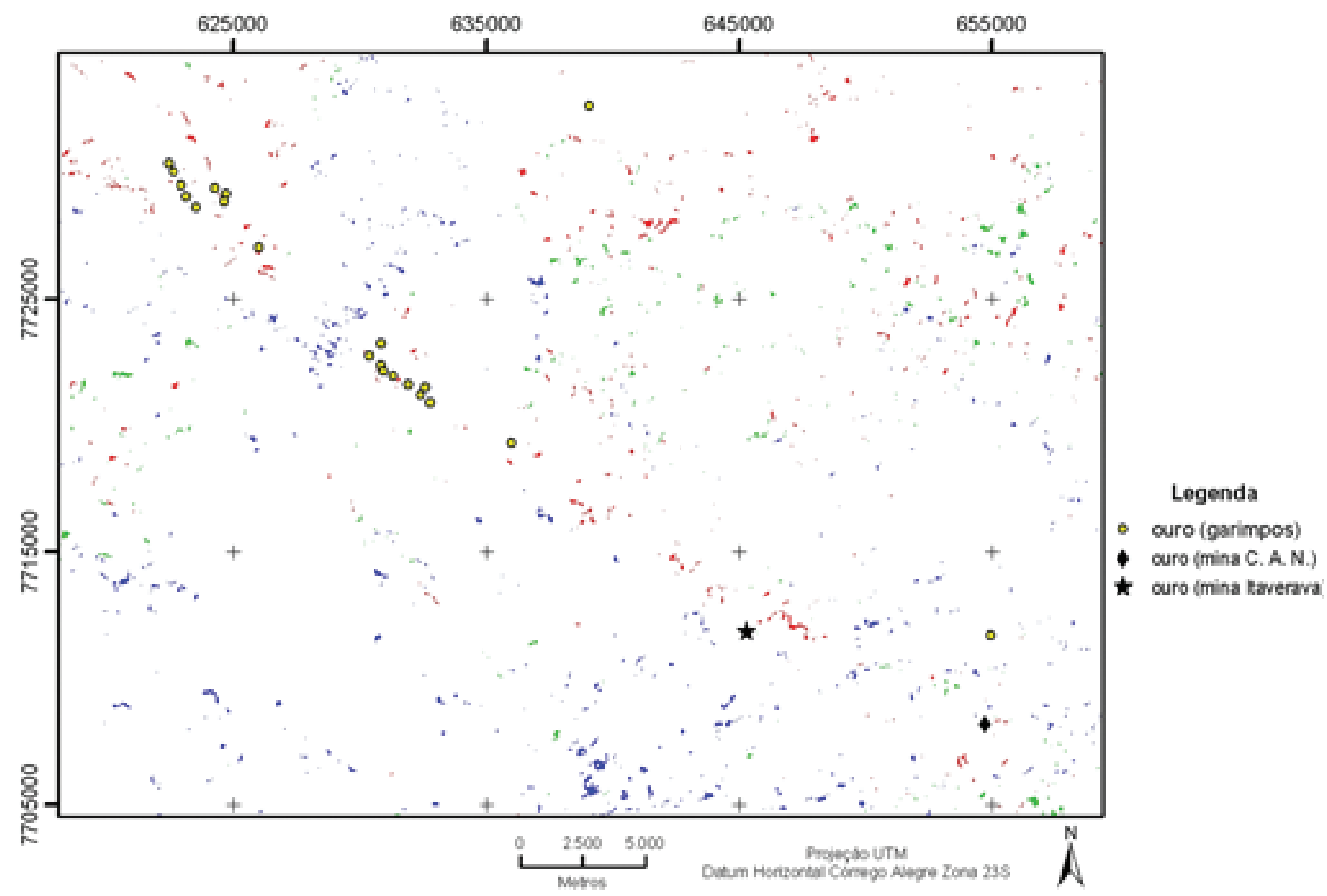

Figura 9 - Resultado obtido com o método de classificação SAM para o mapeamento de áreas com assinatura geofisica (gamaespectrométrica e magnetométrica) similar às dos pontos de treinamento (garimpos e minas de ouro de Itaverava e Catas Altas da Noruega), definidos como alvos 1, 2 e 3, respectivamente. Dados utilizados: canais de $K$, The $U$ e amplitude do sinal analítico. C. A. N. - Catas Altas da Noruega. (imagem colorida disponível na versão on-line)

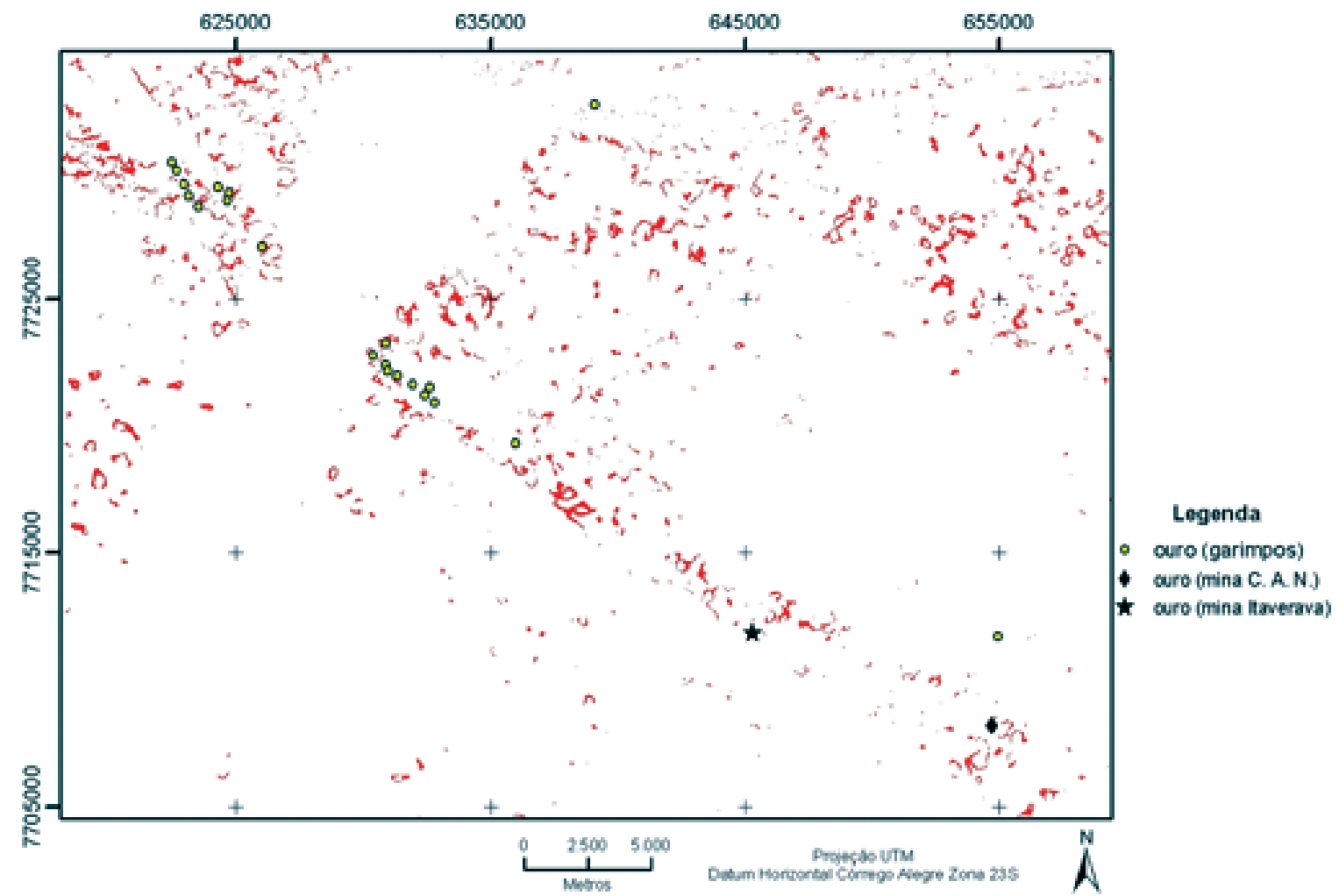

Figura 10 - Resultado obtido com o método MTMF para o mapeamento de áreas com assinatura geofisica similar à dos pixels dos garimpos de ouro. (imagem colorida disponivel na versão online) 


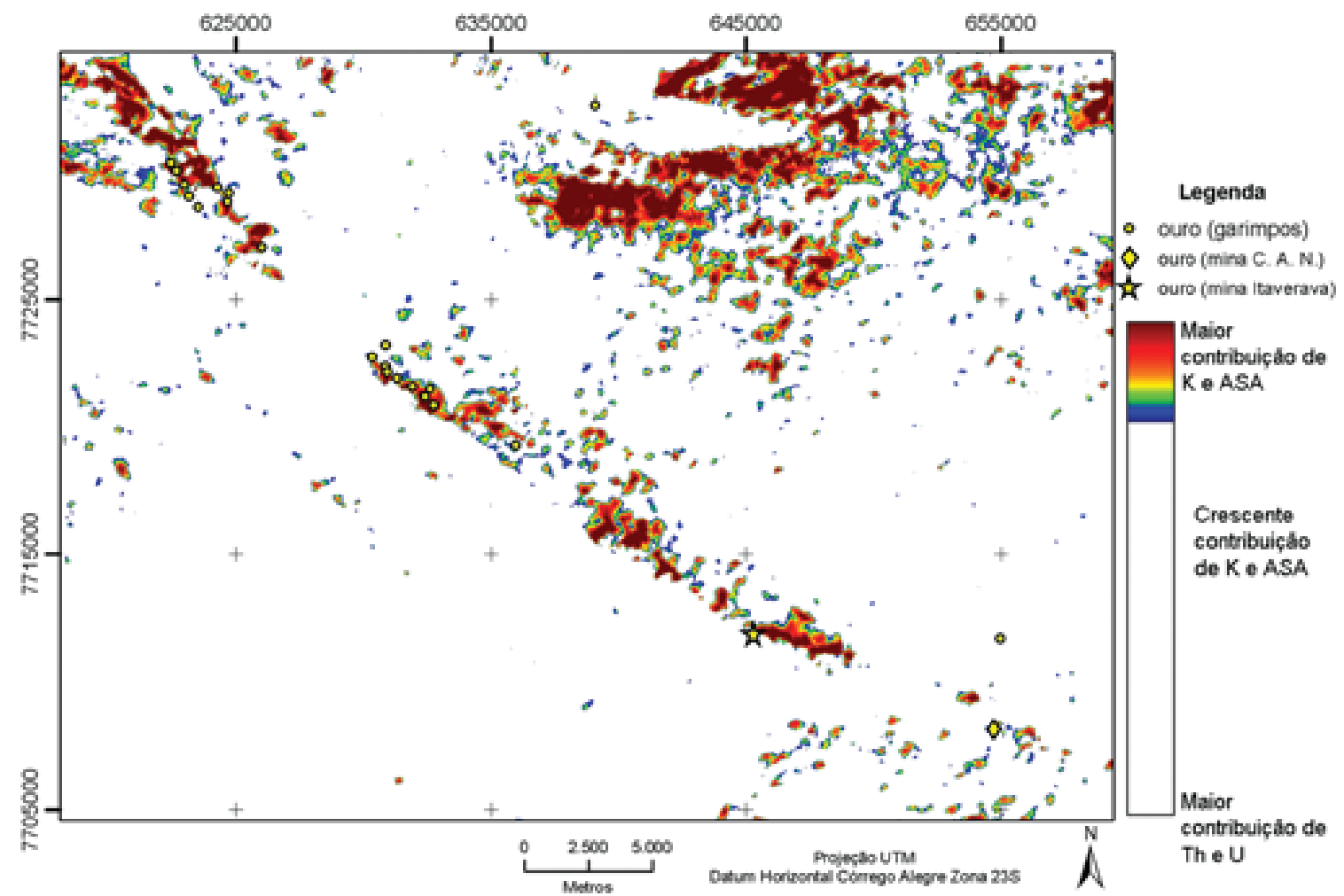

Figura 11 - Segunda principal componente (PC2). O histograma da imagem foi ajustado de modo a realçar áreas enriquecidas em $K$, de elevada susceptibilidade magnética (ASA) e pobres em $T h$ e U. (imagem colorida disponível na versão on-line)

conhecidas da área (garimpos e minas) são hospedadas por rochas da zona de cisalhamento que define o Lineamento Congonhas. A associação é apontada em diversos produtos gerados: (i) nos mapas dos canais de $\mathrm{K}$ e K/Th e da amplitude do sinal analítico, nos quais os pontos coincidem com as áreas de maiores valores (respectivamente, $0,5 \%, 0,08$ e $120 \mathrm{nT} / \mathrm{m}$ ); (ii) nos mapas de derivada vertical e gradiente horizontal total do campo magnético anômalo e de lineamentos interpretados nos mosaicos dos sensores orbitais, nos quais situamse sobre ou adjacentes às estruturas de grande e médio porte que definem a zona de cisalhamento.

É notável que as áreas caracterizadas como mais prospectivas coincidam igualmente com a zona de cisalhamento nos produtos gerados subseqüentemente - tanto os resultados dos métodos data-driven, nos quais se predefiniram os endmembers associados às ocorrências de ouro (classificação não-supervisionada do tipo Isodata e classificações supervisionadas SAM e MTMF), quanto daqueles knowledge-driven, conduzidos sem a utilização de pontos de treinamento (Lógicas Booleana e Fuzzy e Análise por Principais Componentes).

Devido às assinaturas geofísicas que as individualizam (semelhantes aos pontos nos quais ocorrências de ouro são documentadas), diversas áreas ao longo do Lineamento Congonhas, definidas como alvos podem ser representativos de rochas afetadas pela instalação desta estrutura de cisalhamento.

Pixels assinalados como alvos de elevada favo- rabilidade que se situam em áreas distantes e, portanto, não influenciadas pelo lineamento, devem ser interpretados com cautela. Podem representar rochas com assinaturas geofísicas semelhantes às mineralizadas, mas não terem sido percoladas por fluidos mineralizantes e, conseqüentemente, não hospedarem ouro.

CONCLUSÕES Os resultados obtidos através da modelagem pelos métodos knowledge-driven, baseados em diversos planos de informação, permitem destacar algumas importantes implicações do estudo. A primeira consideração diz respeito ao modelo descritivo empírico-teórico considerado para depósitos de ouro do tipo lode, o qual norteou as análises espaciais guiadas pelo conhecimento. Utilizando-se das assinaturas geofísicas das rochas envolvidas e da correlação espacial das mineralizações com falhas e zonas de cisalhamento, o modelo apresentou bom desempenho na localização dos depósitos já conhecidos, demonstrando ser consistente com a situação geológica existente na área de estudo (presença do Lineamento Congonhas e processo hidrotermal associado).

Sítios favoráveis à prospecção de ouro, muito similares àqueles apontados pelas demais técnicas, foram obtidos também pelos classificadores hiperespectrais adaptados (métodos data-driven), indicando que os mesmos podem ser utilizados alternativamente como uma rápida ferramenta em prospecção.

Os modelos originados nessa pesquisa indicam a presença de áreas com elevado potencial de prospec- 
tividade, as quais, no entanto, ainda não foram reconhecidas em trabalhos anteriores - uma informação que poderá auxiliar trabalhos de exploração regional nessa porção do CSF.

Destaca-se ainda que a inclusão de mais dados no modelo descritivo, tais como dados geoquímicos, geológicos e metalogenéticos detalhados, poderiam contribuir para que o mesmo fosse ainda mais representativo da realidade das mineralizações e rochas hospedeiras.

Demonstrou-se que os métodos podem ser aplicados, com sucesso, em áreas de difícil acesso e espesso manto de intemperismo, que dificultam pesquisas baseadas em métodos tradicionais de mapeamento e avaliação de recursos minerais.

Agradecimentos A CODEMIG e a SEME (Secretaria de Minas e Metalurgia) de Minas Gerais pela disponibilização dos dados aerogeofísicos, em particular ao Dr. Marcelo Nassif e a Geóloga Andréa Vaz de Melo. À CPRM, em particular a Dr. Mônica Perrota, pela disponibilização dos dados de ocorrências minerais do Estado de Minas Gerais. A FAPESP, pelo financiamento da pesquisa através do Auxílio Proc. No 02 09038-6. C. Miethke agradece ao CNPq-Pibic pela concessão de bolsa de IC. C.R. Souza Filho agradece ao CNPq pela bolsa de Produtividade em Pesquisa (Proc. N ${ }^{\circ}$ 301.227/94).

\section{Referências}

Adams J. A. S., Gasparini P. 1970. Gamma-ray spectrometry of rocks. Elsevier Publ. Co., New York, 295 p.

Boardman J. W., Kruse F. A., Green R. O. 1995. Mapping target signatures via partical unmixing of AVIRIS data. In: Summaries, Fifth JPL Airborne Earth Science Workshop, JPL Publication 95-1, v. 1, pp.: 23-26.

Bonham-Carter G. F. 1994. Geographic Information Systems for geoscientists - Modeling with GIS. Pergamon, 400 p.

Boyd D. M. 1984. Aeromagnetic surveys and gold. In Doyle H. A.. 1984 (ed.), Geophysical exploration for Precambrian gold deposits. The University of Western Australia, Publication n. 10.

Chen J.Y.; Reed I.S. 1987. A detection algorithm for optical targets in clutter. IEEE Transactions on Aerospace and Electronic Systems, AES-23(1):46-- 59, 1987.

COMIG - Companhia Mineradora de Minas Gerais, 2003. Mapa Geológico do Estado de Minas Gerais, Brasil, escala 1:1.000.000. Belo Horizonte, MG.

Dorr II J.V.N .1969. Physiographic, stratigraphic and structural development of the Quadrilátero Ferrifero, Minas Gerais, Brazil. Washington. U.S. Geol. Surv. Prof. Pap., 641-A.110p.

Drury, S.A. (2001). Image Interpretation in Geology. Third Edition. Blackwell Science., 290p.

Groves D. I., Phillips N., Ho S. E., Houston S. M., Standing C. A. 1987. Craton-scale distribution of archean greenstone belt gold deposits: predictive capacity of the metamorphic model. Economic Geology, vol. 82, $\mathrm{n}^{\circ} 8$, pp. 2045-2058.

Hodgson C. J., 1993. Mesothermal lode-gold deposits, in Kirkham S.V., Sinclair W. D., Thorpe R. I., Duke J. M., eds., Mineral Deposit Modeling: Geological Association of Canada, Special Paper 40, p. 635-678.

Hodgson C. J., 1993. Mesothermal lode-gold deposits, in Kirkham S.V., Sinclair W. D., Thorpe R. I., Duke J. M., eds., Mineral Deposit Modeling: Geological Association of Canada, Special Paper 40, p. 635-678.

Hutchinson R. W. 1987. Metallogeny of precambrian gold deposis: space and time relationships. Economic Geology, v. 82, n 8, pp. 1993-2007.
Killeen P.G. 1979. Gamma Ray Spectrometric Methods In Uranium Exploration - Application And Interpretation. In: Hood, P.J. (Ed.) 1979. Geophysics And Geochemistry In The Search For Metallic Ores. Economic Geology Report, 31, GSC, P.163-229.

Knox-Robinson C. M., Groves, D. I. 1997. Gold prospectivity mapping using a Geographic Information System (GIS) with examples from the Yilgarn Block of Western Australia. Chronique de la Recherche Miniere, 529, p. 127-138.

Kruse F. A., Lefkoff A. B., Boardman J. B., Heidebrecht K. B., Shapiro A. T., Barloon P. J., Gotees A. F. H. 1993. The spectral image procecssing system (SIPS) - Interactive visualization and analysis of imaging spectrometer data. Remote Sensing of Environment. Special issue on AVIRIS, May-June 1993, v. 44, pp. 145-163.

Lasa Engenharia e Prospecções S.A. 2001. Relatório final do levantamento e processamento dos dados magnetométricos e gamaespectrométricos. Levantamento Aerogeofísico de Minas Gerais, Área 2. Projeto Pitangui - São João Del Rey - Ipatinga. Volume I, Texto técnico.

Minty B.R.S. 1991. Simple Micro-Levelling For Aeromagnetic Data. Expl. Geoph. 22:591-592.

Pires A. C. B. 1995. Identificação Geofísica De Áreas De Alteração Hidrotermal, Crixás-Guarinos, Goiás. Rev. Bras. Geoc., 25(1): 61-68.

Quadros T. F. P., Koppe J. C., Strieder A. J., Costa, J. F. C. L. 2003. Gamma-ray data processing and integration for lode-Au deposits exploration. Natural resources research, vol. 12, $\mathrm{N}^{\circ}$ 1, March 2003.

Seixas L. A. R. 1988. Geologia e metalotectos de ouro de uma fração do Lineamento Congonhas, Minas Gerais. Instituto de Geociências, UnB, Brasília, Dissertação de Mestrado, 119p.

Souza Filho, C. R. . O Relevo das Américas das Américas Como Nunca Antes Visto. Revista Infogeo, São Paulo, v. 5, n. 30, p. 62-64, 2003.

Manuscrito AE-080/2006

Submetido em 12 de março de 2007 Aceito em 07 de agosto de 2007 